\title{
Root curvature localizations as indicators of post length in various tooth groups
}

Perez E, Zillich R, Yaman P. Root curvature localizations as indicators of post length in various tooth groups. Endod Dent Traumatol 1986; 2: 58-61.

Abstract - The straight line length available for post preparations in pulps of 957 human teeth was evaluated. Analysis of radiographs in both buccolingual and mesiodistal directions showed that only $2.7 \%$ of the teeth studied were straight to the apex in both views. Average straight line lengths were calculated for the different types of teeth and used to offer guidelines for the length of post preparation. Buccal roots of maxillary molars and the mesial roots of the mandibular molars frequently showed straight line lengths insufficient for post preparations.

\section{Enrique Perez, Richard Zillich and Pe- ter Yaman*}

University of Michigan, Department of Endodontics, and ${ }^{\star}$ Department of Operative Dentistry, Ann Arbor, Michigan, USA

Key words: root canal posts, tooth roots, root curvature.

Richard Zillich, D. D. S., M. S., Department of Endodontics, University of Michigan, School of Dentistry, Ann Arbor, MI 48109, USA.

Accepted for publication 28 October 1985.
Many aspects of post preparation have been studied. Most of the studies have concerned themselves with retention and stress distribution of the post. Studies on the length of the post and its relationship to an endodontic seal have led to various results $(1-5)$. However, little is known about the relationship of post preparation and anatomical variations. Hunter (6) has reported that, after endodontic preparation, only a very thin layer of dentin may remain in the mesial root of mandibular molars between the root canal and the cementum on the distal aspect of the root. He also reported frequent perforations in this area. Abou-Rass and coworkers (7) have suggested an anticurvature method of filing to minimize this.

Schneider (10) suggested the use of the radiographic image of the roots to classify root curvatures into 3 groups: straight, moderate and severe curvature. Clearly, however, radiographs show only two dimensions of a three-dimensional object. Zillich \& Corcoran (8) have found that a post length nominally one-half of the root length would not normally jeopardize an apical seal of $5 \mathrm{~mm}$. Zillich \& Yaman (9), in a study of bi-rooted maxillary premolars, found that the lingual root was the straightest of the 2 roots and that the post preparation on the average should not be closer than $6 \mathrm{~mm}$ to the apex. This last named study used radiographic assessment of the straight line part of the root canal. In the present study, similar measurements were performed to determine the straight line root space available for a post in different groups of human teeth using 2 different radiographic projections.

\section{Material and methods}

The study used 957 extracted human teeth. The following numbers of teeth of each type were used: 100 each of mandibular molars, canines, incisors and maxillary central and lateral incisors; 95 mandibular first premolars; 92 maxillary canines; 87 maxillary second premolars; 70 maxillary first premolars; 66 maxillary molars and 47 mandibular second premolars. The 957 teeth yielded 1359 completely formed root canals. The teeth were obtained from the University of Michigan School of Dentistry
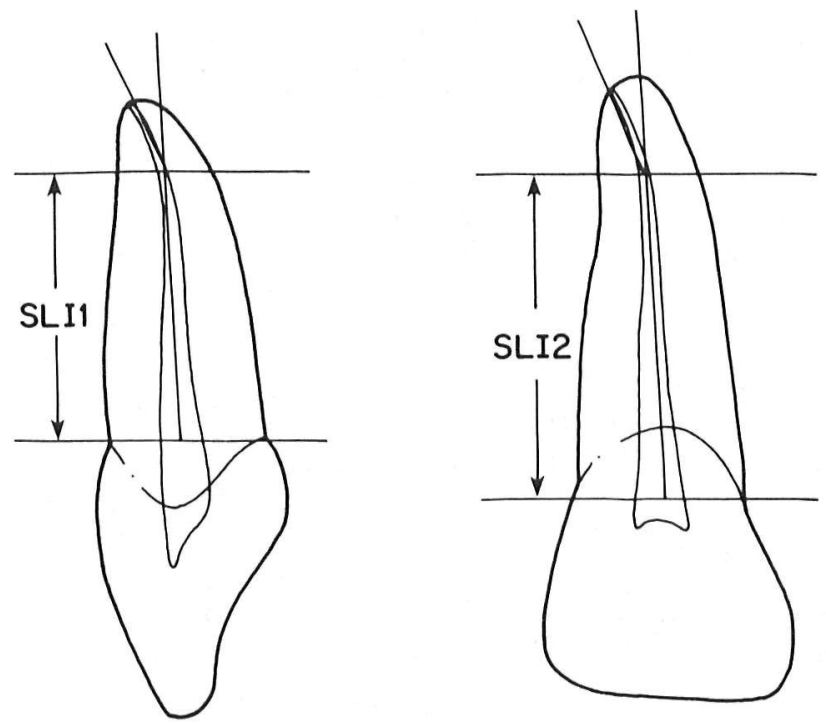

Fig. 1. Schematic representation of measurements for a tooth with a single canal. 

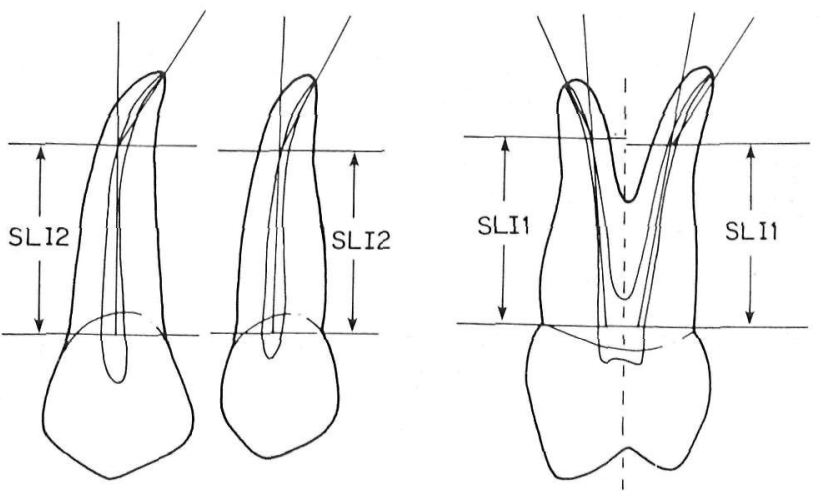

Fig. 2. Schematic representation of measurements for a tooth with 2 canals.

reserves. The reason for extraction and the age of the patient were not known.

Each tooth was radiographed from 2 directions: 1. - the proximal (mesiodistal), and 2. - the buccal (buccolingual). The mandibular molar presented difficulties in taking measurements of the canals in the mesial root due to the overlapping of the canals. Because of this, the tooth was radiographed with a slightly distal horizontal angulation in order to separate the two mesial canals on the radiograph. Each radiograph was taken using a standardized technique with a Philips Oralix 65 (Philips Medical Systems, Shelton, CT). The radiographs were de-

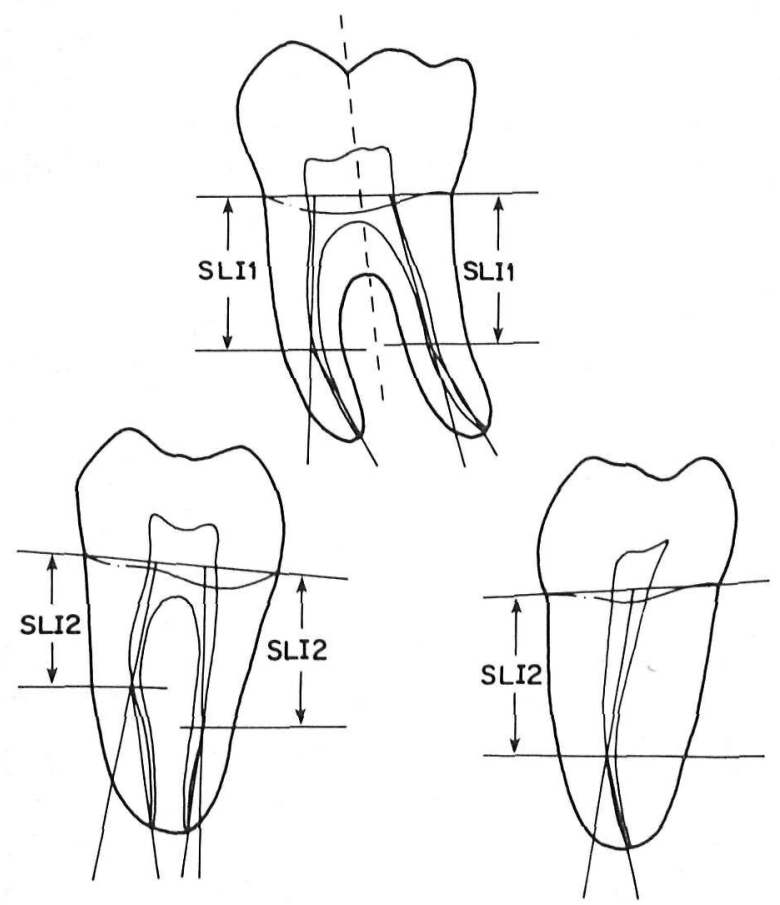

Fig. 3. Schematic representation of measurements for a mandibular molar.
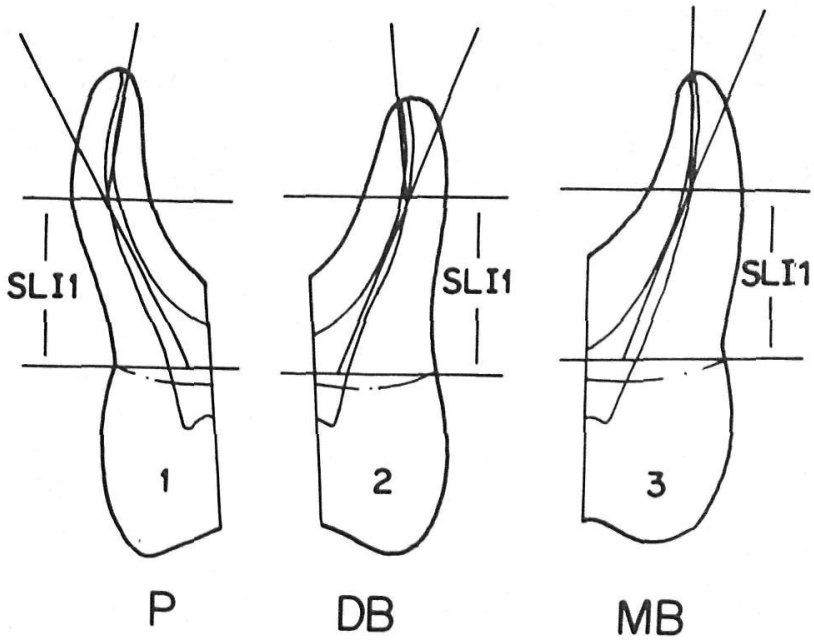

Fig. 4. Schematic representation of the proximal view measurements for a maxillary molar.

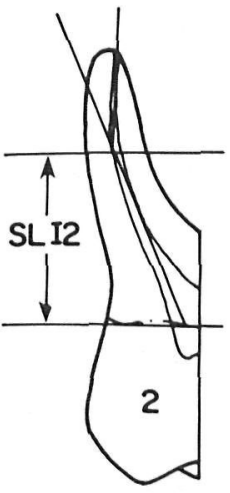

DB

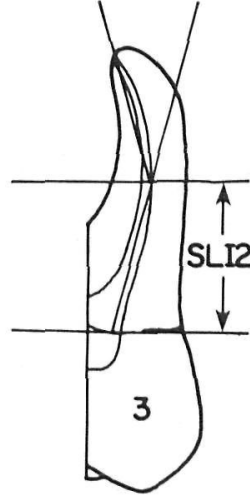

$\mathrm{MB}$

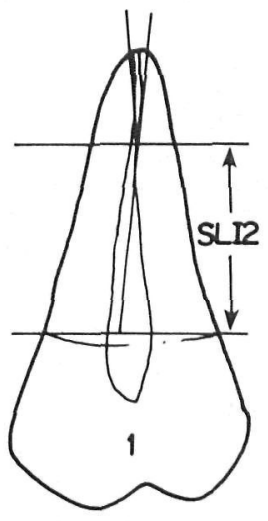

$P$
Fig. 5. Schematic representation of the facial view measurements for a maxillary molar.

veloped under standardized conditions using an automatic X-ray film processor (Philips Model 810Philips Medical Systems, Shelton, CT). A total of 2718 X-rays were taken and analyzed, using the Schneider method (10) with the aid of a projector increasing the size of the tooth by 10 times. First, a line was scribed on the radiograph parallel to the tooth's long axis. A second line was then drawn from the canal at the apex to the first line where it began to intersect with the root dentin. A third line was drawn to connect the cemento-enamel junctions (CEJ) in each view. Figs. 1-5 are schematic representations of how this was accomplished. Measurements of the distance between the line connecting the GEJ and the intersection of the lines scribed on the canal were taken and recorded. The distance recorded on the mesiodistal view was la- 
Perez et al.

Table 1. Measurements of straight line lengths of maxillary root canals. SLI 1 - mesiodistal projection; SLI 2 - buccolingual projection

\begin{tabular}{|c|c|c|c|c|c|c|c|c|c|}
\hline & & & & & & & & & \\
\hline & & Min & Max & Mean & Std dev. & t-test & $\mathrm{p}$-value & Correlation & \\
\hline Central & SLI 1 & 6.7 & 12.8 & 9.7 & 1.3 & -7.8094 & 0.0000 & $0.6650^{\star}$ & $(0.3120)^{\star \star}$ \\
\hline Incisor & SLI 2 & 8.7 & 15.9 & 11.4 & 1.4 & & & & \\
\hline Lateral & SLI 1 & 6.0 & 15.2 & 9.8 & 1.6 & 14600 & 0,0000 & $06606^{*}$ & $(02632)^{\star \star *}$ \\
\hline Incisor & SLI 2 & 6.6 & 14.6 & 11.8 & 1.3 & 1.4000 & 0.0000 & 0.0000 & $(0.2032)$ \\
\hline Canines & SLI 1 & 8.6 & 18.2 & 12.8 & 1.9 & -31353 & 0.0028 & $06402^{*}$ & $(02732)^{\star \star}$ \\
\hline Canmines & SLI 2 & 9.0 & 17.8 & 13.6 & 1.8 & -0.1300 & $0.00<8$ & 0.0402 & $(0.2132)$ \\
\hline Buccal root & SLI 1 & 6.1 & 13.7 & 9.6 & 1.5 & -15296 & 0.0322 & $02745^{*}$ & (02706)** \\
\hline first premol. & SLI 2 & 6.5 & 14.5 & 9.9 & 1.8 & -1.0290 & 0.0322 & 0.2145 & $(0.270 \mathrm{~b})$ \\
\hline Lingual root & SLI 1 & 6.3 & 12.8 & 9.5 & 1.4 & -13865 & 0.1713 & $02431^{*}$ & \\
\hline first premol. & SLI 2 & 4.6 & 14.1 & 9.6 & 1.6 & -1.0000 & 0.1713 & 0.2431 & $(0.2681)$ \\
\hline Second & SLI 1 & 7.2 & 15.0 & 10.7 & 1.6 & 1.9360 & 0.0570 & $0.4325^{*}$ & $(0.2369)^{\star \star}$ \\
\hline premolar & SLI 2 & 6.9 & 15.1 & 10.2 & 1.4 & 1.0000 & 0.0070 & $0.40<J$ & \\
\hline Max. molar & SLI 1 & 5.7 & 11.5 & 7.9 & 1.4 & 82134 & 00000 & $03685^{*}$ & $(02500)^{\star \star}$ \\
\hline mesiobuccal root & SLI 2 & 4.2 & 10.1 & 6.5 & 1.1 & 0.2104 & 0.0000 & 0.3085 & $(0.2500)$ \\
\hline Max. molar & SLI 1 & 5.6 & 11.8 & 8.6 & 1.2 & -5.1104 & 0.0000 & $0.1032^{*}$ & $(0.3291)^{\star \star}$ \\
\hline distobuccal root & SLI 2 & 5.2 & 12.1 & 7.6 & 1.2 & & & & \\
\hline Max. molar & SLI 1 & 6.8 & 12.0 & 9.2 & 1.1 & -6.6282 & 0.0000 & $0.4865^{\star}$ & $(0.3291)^{\star \star}$ \\
\hline palatal root & SLI 2 & 7.7 & 13.7 & 10.7 & 1.5 & & & & \\
\hline
\end{tabular}

** Critical value for the correlation coefficent at the $5 \%$ level of significance.

Table 2. Measurements of straight line lengths of mandibular root canals. SLI 1 - mesiodistal projection; SLI 2 - buccolingual projection

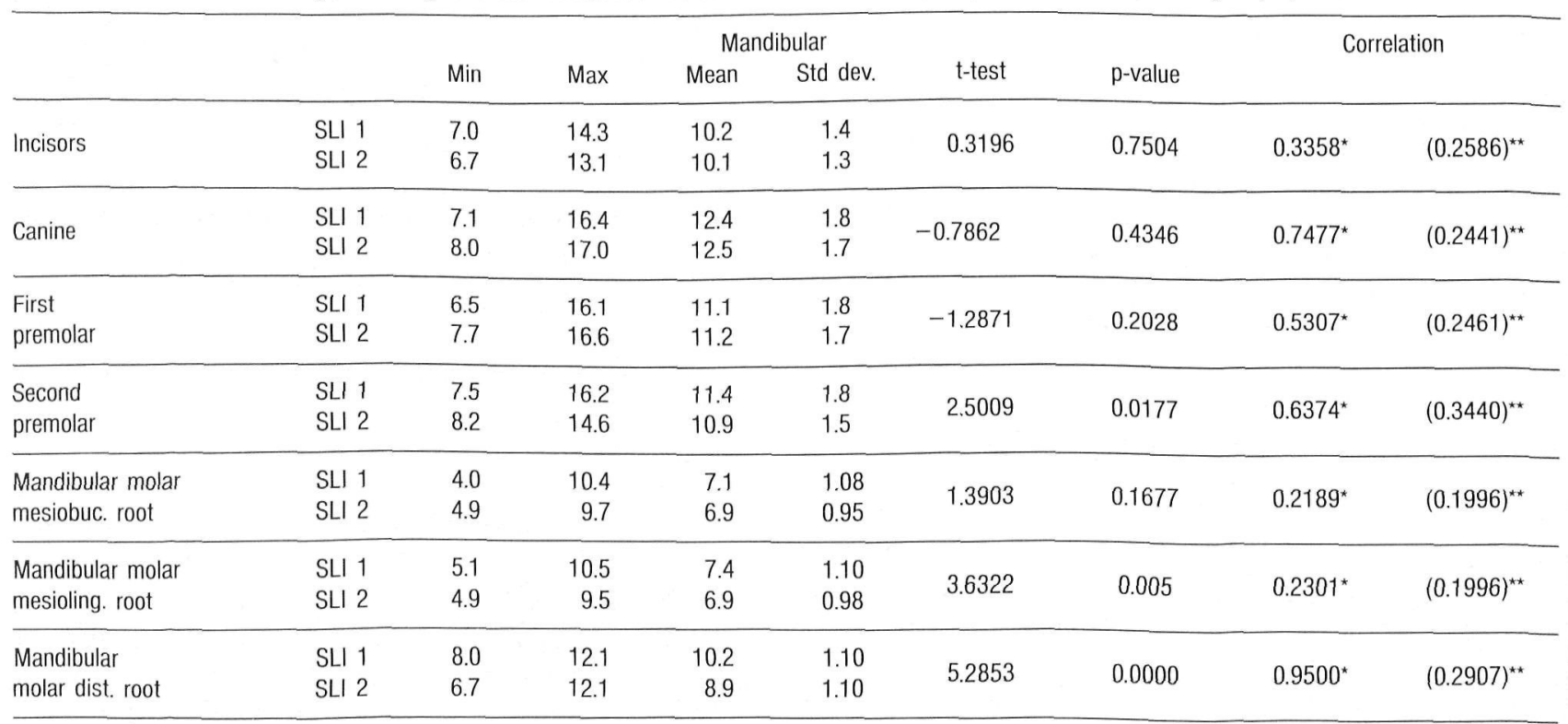

** Critical value for the correlation coefficient at the $5 \%$ level of significance. 
beled SLI1. The distance was labeled SLI2 on the buccolingual view for each root. The mandibular central and lateral incisors, the maxillary molars and the mandibular molars were analyzed together since the anatomy of these teeth is similar.

The following descriptive statistics were calculated for each measurement for each type of tooth: minimum, maximum, mean, and standard deviation. The data obtained from mesiodistal and buccolingual radiographs were compared by use of the pairwise T-test and correlation coefficient.

\section{Results}

The results are compiled in Tables 1 and 2. Roots were straight from the CEJ to the apex $21.1 \%$ of the time in the mesiodistal view and $12.2 \%$ of the time in the buccolingual view. The roots were straight in both views of the same root in only $2.7 \%$ of the teeth examined.

\section{Discussion}

Root canal curvature affects certain restorative procedures, including post preparation. In clinical practice, thinning and perforations of the root may occur because of lack of awareness of the natural dimensions of the tooth. The data in the present study may be used to offer some guidelines for post lengths based on the curvature measurements for the different groups of teeth in the human dentition.

Analysis of the results showed that, while some teeth appear to be straight in one view (mesiodistal or buccolingual), very few teeth were straight in both views. In part, this could be due to the broader form of many canals in the mesiodistal view. The data provided numerical substantiation of the clinical suspicion that a tooth which appears straight in a routine radiograph may be curved in another view.

In some of the teeth, the statistical analysis of SLI1 and SLI2 lengths revealed a significant difference $(p<0.05)$. This difference could in part be due to the normal anatomy of the crown in which the CEJ was more apical in the buccal view than in the mesial view. However, for several tooth groups, particularly in the maxilla, SLI2 was the longer, indicating a greater tendency for early curvature in the mesiodistal view.

The distance from the intersecting point of curvature to the apex was not measured in the present study. Based on published data on root lengths however, (for overview, see Ref. 8), one may compare the average straight line lengths of the present study with earlier suggestions for post lengths (5). First, an overall association between average root length
(8) and straight line length was apparent. However, notable exceptions occurred; e. g., the upper lateral incisor was longer in straight line pulp length than the central incisor. Second, the intersecting point of curvature was on the average located some $5 \mathrm{~mm}$, or slightly less, from the tooth apex. Used conservatively, the present data may therefore aid in selecting post lengths which preserve $5 \mathrm{~mm}$ of intact root filling apically $(1,3,9)$. However, some roots, notably the mesial roots of mandibular molars and buccal roots of maxillary molars, frequently have very short straight line lengths unsuitable for post preparation.

\section{Conclusions}

Based upon the parameters of this investigation, the following conclusions were drawn:

1. Only $2.7 \%$ of the roots examined were straight in both the buccolingual and mesiodistal views.

2. Root curvature occurred most frequently less than $5 \mathrm{~mm}$ from the apex. Leaving at least $5 \mathrm{~mm}$ of gutta-percha apically in the root canal may therefore be a good clinical guide.

3. Straight line lengths of pulps in mesiobuccal and distobuccal roots of maxillary molars and in mesiobuccal and mesiolingual roots of mandibular molars were frequently too short for adequate retention of posts by conventional, clinical criteria.

\section{References}

1. Neagly RL. The effect of dowel preparation on the apical seal of endodontically treated tecth. Oral Surg 1969; 28: $739-45$.

2. Schnell FJ. Effect of immediate dowel space preparation on the apical seal of endodontically filled teeth. Oral Surg $1978 ; 45(3): 470-4$.

3. Mattison GD, Delivanis PD, Thacker RW, Hassell KJ. Effect of post preparation on the apical seal. I Prosth Dent $1984 ; 51(6): 785-9$

4. Jerome JK. An evaluation of the support structure for post preparations. Master's Thesis, Ann Arbor, The University of Michigan, 1980, $\mathrm{V}+48 \mathrm{p}$.

5. Weine FS. Endodontic Therapy. 3rd ed. St. Louis: CV Mosby, $1982,593-601$.

6. Hunter JK. Mechanical preparation of fincly curved canals of mandibular molars. Master's Thesis, Ann Arbor, University of Michigan, 1981, VIII +64p.

7. Abou-Rass M, Frank AL, Glick DH. The anticurvature filing method to prepare the curved root canal. JADA 1980; $101(5): 792-4$.

8. Zillich RM, Corcoran JF. Average maximum post lengths in endodontically treated teeth. I Prosth Dent 1984; 52: 48991.

9. Zillich RM, Yaman P. Effect of root curvature on post length in the restoration of endodontically treated premolars. Endod Dent Traumatol 1985; 1: 135-7.

10. Schneider SW. A comparison of canal preparations in straight and curved root canals. Oral Surg 1971; 32: $271-5$. 
This document is a scanned copy of a printed document. No warranty is given about the accuracy of the copy. Users should refer to the original published version of the material. 